\title{
LETTERS
}

\section{Effects of helmet use on costs of motorcycle crashes}

We read with interest the recent valuable contribution to road safety and injury prevention literature by Pincus and colleagues. ${ }^{1}$ There is considerable evidence that appropriate helmet use greatly alleviates the burden of motorcyclists' injuries. Previous studies have also shown that motorcyclists who do not wear helmets have more severe injuries (including traumatic brain injuries), resulting in higher health care costs and an increased likelihood of requiring care beyond the hospital. ${ }^{2,3}$ Therefore, it is appropriate and more sensible that we calculate and compare the cost to our health care system of injuries received by motorcyclists using helmets against those received by motorcyclists without helmets. There is definitive evidence that helmets reduce mortality, traumatic brain injury and hospital expenditures. ${ }^{3}$

The main limitation of the study by Pincus and colleagues ${ }^{1}$ is that the authors did not separate the costs associated with use of protective devices by injured motorcyclists, despite a 2012 systematic review and meta-analysis showing that motorcycle helmet use reduces morbidity and contributes to substantial health care cost savings. ${ }^{2}$ According to this systematic review, the mean total hospital charge for motorcyclists involved in a crash was $\$ 4184.26$ for those who wore helmets and $\$ 7383.31$ for those who did not. If Pincus and colleagues had separated their data to compare the costs of motorcycle crashes between those who wore helmets and those who did not, it would have been a helpful contribution to the decade-long debate on the value of appropriate helmet use to traffic safety. ${ }^{1,2,4}$

Analysis of data related to trauma from motorcycle crashes has shown that motorcyclists are more than 3.5 times as likely to die or become injured when compared with other motor vehicle drivers, ${ }^{5}$ and the main cause of death was a head injury, whereas lower-limb injuries account for most hospital admissions. ${ }^{5}$ Use of protective devices, namely helmets, has been shown to prevent injury, disability and death by reducing serious head injuries. ${ }^{6,7}$ Therefore, "all operators and riders of motorcycles are required by
Ontario provincial law to wear a helmet when on a motorcycle or motor-assisted bicycle."

Worldwide, motorcyclists who do not wear helmets are at high risk for serious injury and death in the event of a crash, which places excessive economic burden on society through costly medical interventions and long-term disability. ${ }^{9}$ A Cochrane systematic review concluded that helmets reduced the risk of head injury by about $69 \%$ and death by about $42 \%$ among motorcyclists. ${ }^{10}$

\section{Ediriweera Desapriya PhD}

Research associate

\section{Sarah Yassami MD}

Research assistant

\section{Gooya Sheikhimoghadam MD}

Research assistant, Department of Emergency Medicine, Faculty of Medicine, University of British Columbia, Vancouver, BC

- Cite as: CMAJ 2018 May 22;190:E626. doi: 10.1503/cmaj.68734

\section{References}

1. Pincus D, Wasserstein D, Nathens AB, et al. Direct medical costs of motorcycle crashes in Ontario. CMAJ 2017;189:E1410-5.

2. Heldt KA, Renner CH, Boarini DJ, et al. Costs associated with helmet use in motorcycle crashes: the cost of not wearing a helmet. Traffic Inj Prev 2012;13:144-9.

3. Crompton JG, Bone C, Oyetunji T, et al. Motorcycle helmets associated with lower risk of cervical spine injury: debunking the myth. J Am Coll Surg 2011;212:295-300.

4. Kim CY, Wiznia DH, Averbukh L, et al. The economic impact of helmet use on motorcycle cccidents: a systematic review and meta-analysis of the literature from the past 20 years. Traffic Inj Prev 2015;16:732-8.

5. Monk JP, Buckley R, Dyer D. Motorcycle-related trauma in Alberta: a sad and expensive story. Can J Surg 2009;52:E235-40.

6. Ameratunga S, Jackson R, Norton R. Death and injury on roads. BMJ 2006;333:53-4.

7. Peden M, Scurfield R, Sleet D, et al., editors. World report on road traffic injury prevention. Geneva: World Health Organization; 2004.

8. Motorcycles handbook. Ontario: Ontario Ministry of Transportation; 2009. Available: www.mto.gov. on.ca/english/handbook/motorcycles/section2-5-0. shtml (accessed 2018 Dec. 7)

9. Eastridge BJ, Shafi S, Minei JP, et al. Economic impact of motorcycle helmets: from impact to discharge. J Trauma 2006;60:978-83, discussion 983-4.

10. Liu BC, Ivers R, Norton R, et al. Helmets for preventing injury in motorcycle riders. Cochrane Database Syst Rev 2008;(1):CD004333.

Competing interests: None declared 